\title{
Redescription of Orobdella octonaria (Hirudinida: Arhynchobdellida: Orobdellidae) with Designation of a Lectotype
}

\author{
Takafumi Nakano \\ Department of Zoology, Graduate School of Science, Kyoto University, Kyoto 606-8502, Japan \\ E-mail:nakano@zoo.zool.kyoto-u.ac.jp
}

(Received 1 November 2011; Accepted 9 April 2012)

\begin{abstract}
An octannulate Orobdella leech, Orobdella octonaria Oka, 1895, is redescribed on the basis of one syntype collected from Hakone, Kanagawa Prefecture, Japan, and two newly obtained specimens, also from Hakone. It is distinguished from the other known species of Orobdella by its octannulate mid-body somites. No holotype of this species was originally designated. The present syntype from Hakone is designated as the lectotype of O. octonaria for the purpose of clarifying its taxonomic status and type locality.
\end{abstract}

Key Words: Hirudinida, Orobdellidae, Orobdella octonaria, redescription, lectotype, Japan.

\section{Introduction}

Orobdella Oka, 1895 is an East Asian genus of terrestrial macrophagous leeches (Sawyer 1986). It has generally been classified in the family Gastrostomobdellidae along with Gastrostomobdella Moore, 1929, another genus of terrestrial macrophagous leeches reported from Southeast Asia and Hawaii (Richardson 1971; Sawyer 1986; Nakano 2011a). Several different systematic positions have been proposed, however, for either Orobdella or this family (Oka 1895; Soós 1966; Richardson 1971; Sawyer 1986), and recent molecular phylogenetic studies have shown that Orobdella is rightfully placed within the suborder Erpobdelliformes (OcegueraFigueroa et al. 2011; Nakano et al. 2012). Nakano et al. (2012) erected the monotypic family Orobdellidae for Orobdella on the basis of its morphology and phylogenetic position, and that classification is followed here.

Orobdella includes nine described species (Oka 1895; Richardson 1975b; Nakano 2010, 2011b, c, 2012). Among them, three species, O. ijimai Oka, 1895, O. octonaria Oka, 1895, and O. whitmani Oka, 1895, were established by Oka (1895) with neither sufficient description of their internal organs nor type designations. Recently, Nakano (2010) redescribed $O$. whitmani and designated a lectotype for it, because specimens from the three syntype localities turned out to include two different species. Based on newly collected topotypes, Nakano (2011c) also redescribed O. ijimai, a species for which the original type series was missing. Richardson (1971) redescribed O. octonaria based on one specimen collected from Nagano Prefecture, Japan, but he examined neither the type series nor specimens collected from its syntype localities. Among Oka's (1895) three species, $O$. octonaria is thus the last species in need of taxonomic revision.
Orobdella octonaria was originally described by Oka (1895) based on three specimens (syntypes) collected from Mt. "Kinkwazan" (sic: "Kinkazan" in the current Japanese orthography), Gifu, Gifu Prefecture, Japan, and the Hakone mountain range, Hakone, Kanagawa Prefecture, Japan. He mentioned that the syntypes were stored at the Museum of the Zoological Institution of the Tokyo Imperial University, which now forms part of the holdings of The University Museum, The University of Tokyo. However, these specimens were not found in the leech collection there in a recent search (Nakano and Itoh 2011). Fortunately, one syntype of O. octonaria collected from Hakone was found in the collections of the National Museum of Nature and Science, Tokyo (NSMT), where most of Oka's leech collection is now deposited (Nakano 2010). In addition, specimens were newly obtained from the locality at which this syntype had been collected. For the purpose of clarifying its taxonomic status and type locality, O. octonaria is redescribed herein based on all these specimens, with a lectotype designation.

\section{Materials and Methods}

Leeches were newly collected from Hakone, Kanagawa Prefecture, Japan (Fig. 1), under rocks along a mountain trail. Altitudes and coordinates for localities were obtained using a Garmin eTrex GPS unit.

Specimens were relaxed by the gradual addition of $95 \%$ ethanol to freshwater. Botryoidal tissue was taken from every specimen for future DNA extraction, and the remaining major portions of the bodies were fixed in $10 \%$ formalin and preserved in $70 \%$ ethanol. Two measurements were taken: body length (BL) from the anterior margin of the oral sucker to the posterior margin of the caudal sucker, and maximum body width (BW). Examination, dissection, and 


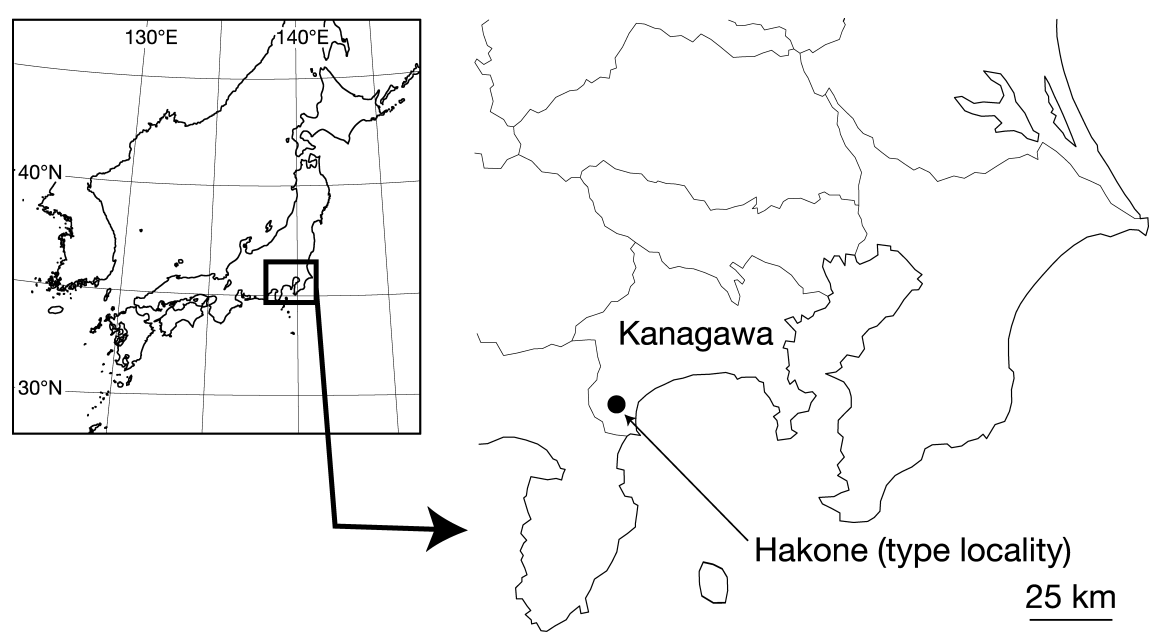

Fig. 1. Map showing the type locality of Orobdella octonaria Oka, 1895.

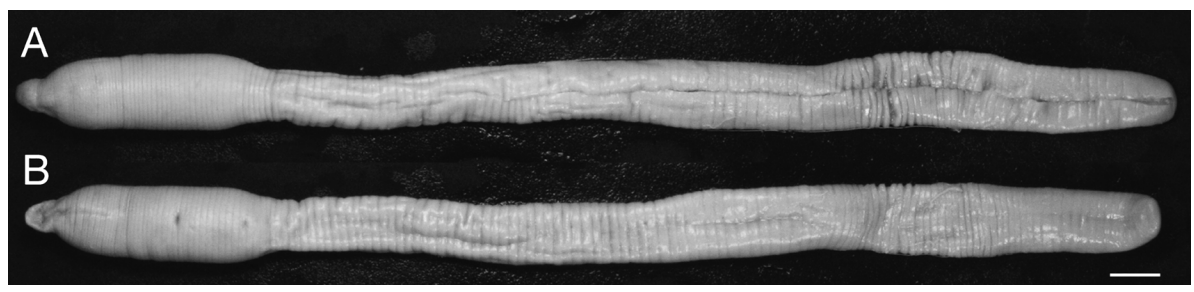

Fig. 2. Orobdella octonaria Oka, 1895, lectotype, NSMT-An 415. A, Dorsal view; B, ventral view. Scale bar: $1 \mathrm{~cm}$.

drawings of the specimens were accomplished under stereoscopic microscopes with drawing tubes (Leica S6E, Leica M125, and Wild Heerbrugg TYP 308700). Except for the syntype of O. octonaria (NSMT-An 415), specimens used in this study have been deposited in the Zoological Collection of Kyoto University (KUZ).

The numbering convention is based on Moore (1927): body somites are denoted by Roman numerals and the annuli in each somite are given alphanumeric designations.

Genus Orobdella Oka, 1895

urn:lsid:zoobank.org:act:FA8333ED-8C17-41FD-AFC162A4F98D4AC1

Orobdella octonaria Oka, 1895 urn:lsid:zoobank.org:act:BFBDD5FB-FCC1-470F-A93C1397F5576C9B

(Figs 2-7)

Orobdella octonaria Oka, 1895: 286-288, pl. 28, figs 3, 1114, pl. 29, fig. C; Oka 1910a: 61; Oka 1910b: 178; Oka and Nagao 1965: 574; Soós 1966: 381, 397; Lukin 1976: 466467; Sawyer 1986: 680, 747.

Kumabdella octonaria: Richardson 1971: 591-599, figs 1-3.

Diagnosis. Somite VII ventrally septannulate (octannulate dorsally). Somites VIII-XXV complete octannulate. Gastropore conspicuous at XIII b2. Gastroporal duct slightly winding at junction with gastropore, tubular but slightly bulbous at junction with crop. Male gonopore at XI c11. Female gonopore inconspicuous at XIII b2. Gonopores separated by $1 / 2$ or $1 / 4+10+1 / 2$ or $3 / 4$ annuli.

Lectotype designation. One syntype, NSMT-An 415, deposited in the NSMT was chosen as the lectotype for $O$. octonaria in this study, since the locality of the specimen is indicated in detail and the syntype is dissectable. NSMT-An 415 was found dissected dorsally from somite XVII c9 to the caudal sucker (Fig. 2A), and labeled as 'type'. The specimen was collected from Mt. Yusakayama, Hakone, Kanagawa Prefecture, Japan.

Material examined. Lectotype: NSMT-An 415, a mature specimen of $221.8 \mathrm{~mm}$ in $\mathrm{BL}$, dissected, collected from Mt. Yusakayama (coordinates of the crest: $35^{\circ} 13^{\prime} 41^{\prime \prime} \mathrm{N}$, $\left.139^{\circ} 04^{\prime} 46^{\prime \prime} \mathrm{E}\right)$, Hakone, Kanagawa Prefecture, Japan, on 1 June 1894. Additional material: two specimens collected from under rocks along a mountain trail at Mt. Sengenyama, Hakone, Kanagawa Prefecture, Japan, by Takafumi Nakano on 7 July 2011: KUZ Z181 (alt. $585 \mathrm{~m}, 35^{\circ} 14^{\prime} 03^{\prime \prime} \mathrm{N}$, $139^{\circ} 04^{\prime} 12^{\prime \prime} \mathrm{E}$ ), dissected, and Z182 (alt. $577 \mathrm{~m}, 35^{\circ} 14^{\prime} 04^{\prime \prime} \mathrm{N}$, $\left.139^{\circ} 04^{\prime} 13^{\prime \prime} \mathrm{E}\right)$.

Description of lectotype. Body firm, muscular, elongated, gaining regularly in width in caudal direction, dorsoventrally depressed, sides nearly parallel from midlength to point just anterior of caudal sucker, BL $221.8 \mathrm{~mm}$, BW $15.0 \mathrm{~mm}$ (Fig. 2A, B). Caudal sucker ventral, oval, its diameter slightly less than BW (Fig. 2B). Color in life unknown. Color faded in preservative, without any dark lines.

Somite I completely merged with prostomium (Fig. 3A). Somite II uniannulate. Somites III-V biannulate (Fig. 3A, B), V a3 forming posterior margin of oral sucker (Fig. 3B). Somite VI ventrally quadrannulate (sexannulate dorsally), a1 (b1, b2 dorsally) = a2 (b3, b4 dorsally) $>$ b5 =b6; a1 and 

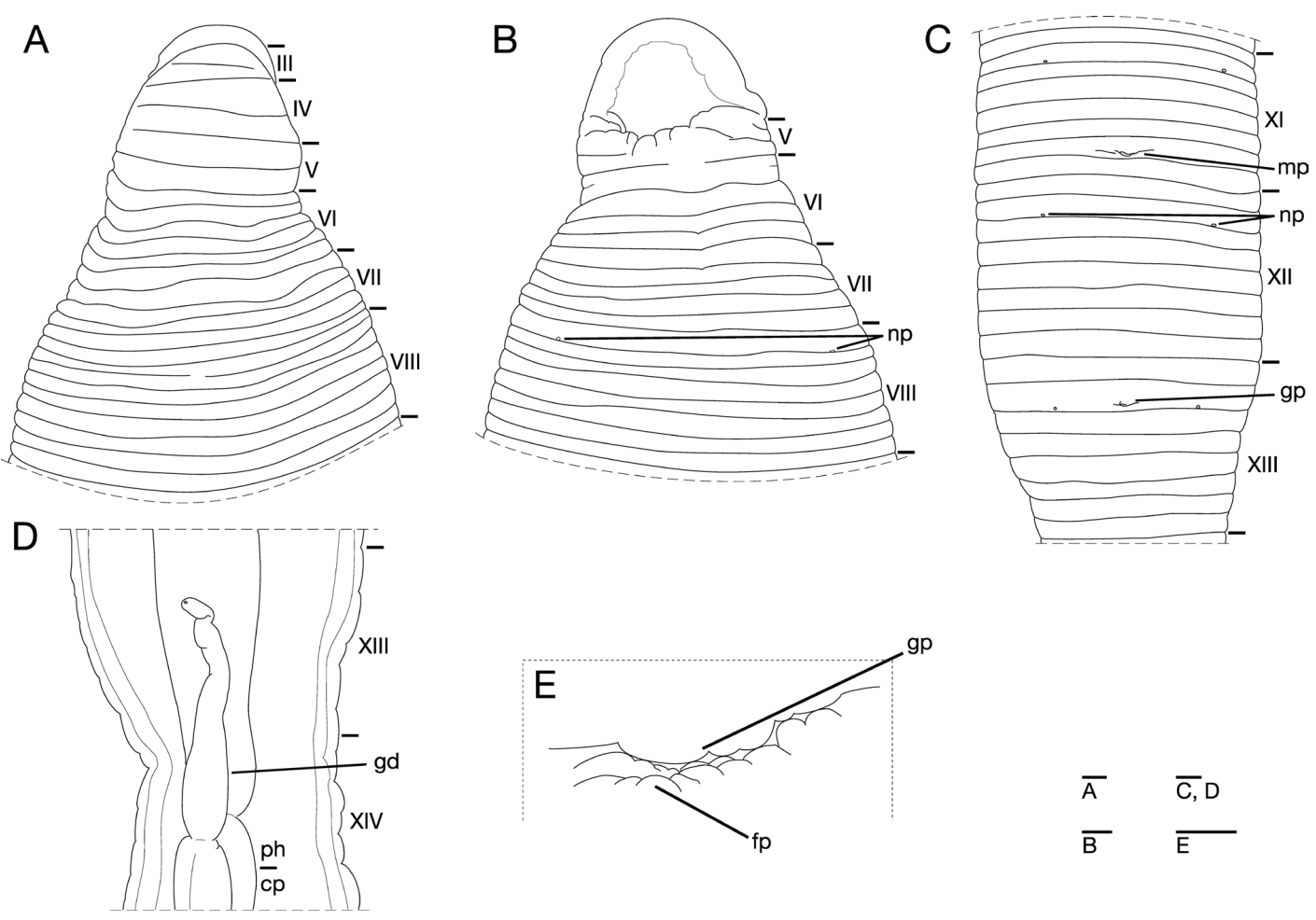

Fig. 3. Orobdella octonaria Oka, 1895, lectotype, NSMT-An 415. A, Dorsal view of somites I-VIII; B, ventral view of somites I-VIII; C, ventral view of somites XI-XIII; D, ventral view of gastroporal duct; E, ventral view of gastropore and female gonopore. Abbreviations: $\mathrm{cp}$, crop; fp, female gonopore; gd, gastroporal duct; gp, gastropore; mp, male gonopore; np, nephridiopore; ph, pharynx. Scale bars: $1 \mathrm{~mm}$ (A-D); $0.25 \mathrm{~mm}(\mathrm{E})$.

a2 with obvious furrow dorsally (Fig. 3A, B). Somite VII quinquannulate, $\mathrm{a} 1>\mathrm{b} 3=\mathrm{b} 4=\mathrm{b} 5=\mathrm{b} 6$ (Fig. 3A, B). Somite VIII ventrally septannulate (octannulate dorsally), a1 (b1, $\mathrm{b} 2$ dorsally $)>\mathrm{b} 3=\mathrm{b} 4=\mathrm{c} 9=\mathrm{c} 10=\mathrm{c} 11=\mathrm{c} 12$; $\mathrm{a} 1$ with obvious furrow dorsally (Fig. 3A, B). Somites IX-XXVI octannulate, $\mathrm{b} 1=\mathrm{b} 2=\mathrm{b} 3=\mathrm{b} 4=\mathrm{c} 9=\mathrm{c} 10=\mathrm{c} 11=\mathrm{c} 12$ (Fig. 3C). Annulation of somite XXVII undecidable, comprised of one annulus (169th) with several slight furrows, 169th annulus being last complete annulus on venter; anus behind it with no postanal annulus.

Anterior ganglionic mass in VI a1. Ganglion VII in a1. Ganglia VIII-XI in b3 and b4 of each somite. Ganglion XII in b3. Ganglion XIII in b4 and c9. Ganglia XIV-XIX in b3 of each somite. Ganglia XX-XXV undetectable. Ganglion XXVI in b4. Posterior ganglionic mass in XXVII.

Eyes not detectable. Nephridiopores in 17 pairs, ventrally at posterior margin of VIII a1, and at posterior margin of b2 of each somite of IX-XXIV (Fig. 3B, C). Papillae numerous, minute, hardly visible, one row on every annulus.

Pharynx agnathous, euthylaematous, reaching to XIV c9/ c10. Crop tubular, acecate, sphincter between crop and intestine undetectable. Gastropore conspicuous, ventral, at posterior of XIII b2 (Fig. 3C, E). Gastroporal duct muscular, slightly winding at junction with gastropore, tubular but slightly bulbous at junction with crop, joining with crop in XIV b4 (Fig. 3D). Intestine and rectum undetectable.

Male gonopore at posterior of XI c11 (Fig. 3C). Female gonopore at posterior of XIII b2, inconspicuous, located diagonally behind gastropore (Fig. 3E). Gonopores separated by $1 / 4+10+3 / 4$ annuli (Fig. 3C). Testisacs undetectable.
Paired epididymides in XVII b1/b2 to XIX b2 (Fig. 4A). Ejaculatory bulbs absent. Ejaculatory ducts in XI c9 to XVII b1/b2, loosely coiled, each widening from junction with epididymis, narrowing at junction with atrial cornu, then turning gradually inward toward atrial cornu without pre-atrial loop (Fig. 4A-D). Pair of atrial cornua in XI c9 to c11, muscular, fusiform (Fig. 4B-D). Atrium body short, muscular, globular in XI C10 and c11 (Fig. 4A-D). Penis sheath and penis absent. Ovisacs one pair, thin-walled, globular, in XIII b3 and b4 (Fig. 4A, E). Oviducts thin-walled, right oviduct crossing ventrally beneath nerve cord, both oviducts converging into common oviduct in XIII b3 (Fig. 4A, E). Common oviduct thin-walled, short, directly descending to female gonopore (Fig. 4E).

Description of other specimens. Maximum BL $132.7 \mathrm{~mm}$, maximum BW $7.71 \mathrm{~mm}$ (Fig. 5A, B). In life, dorsal surface bluish gray without any dark lines (Fig. 6), ventral surface bluish white. Color faded in preservative.

Somite VI ventrally quadrannulate (sexannulate dorsally) (KUZ Z181) (Fig. 7A, B), or ventrally triannulate (quinquannulate dorsally), a1 (b1, b2 dorsally)=a2 (b3, b4 dorsally) $>$ a3 (KUZ Z182). Somite VII ventrally quiquannulate (sexannulate dorsally), a1 (b1, b2 dorsally) $>$ b3 $=\mathrm{b} 4=$ b5=b6; a1 with obvious furrow dorsally (Fig. 7A, B). Somite XXVI octannulate, $\mathrm{b} 1=\mathrm{b} 2=\mathrm{b} 3=\mathrm{b} 4=\mathrm{c} 9=\mathrm{c} 10=\mathrm{c} 11=$ c12, c12 being last complete annulus on venter (KUZ Z181) (Fig. 7C, D), or sexannulate, annulation formula undecidable, composed of six (160th-165th) annuli, 165th annulus being last complete annulus on venter (KUZ Z182). Somite XXVII biannulate (KUZ Z182), or probably triannulate, 

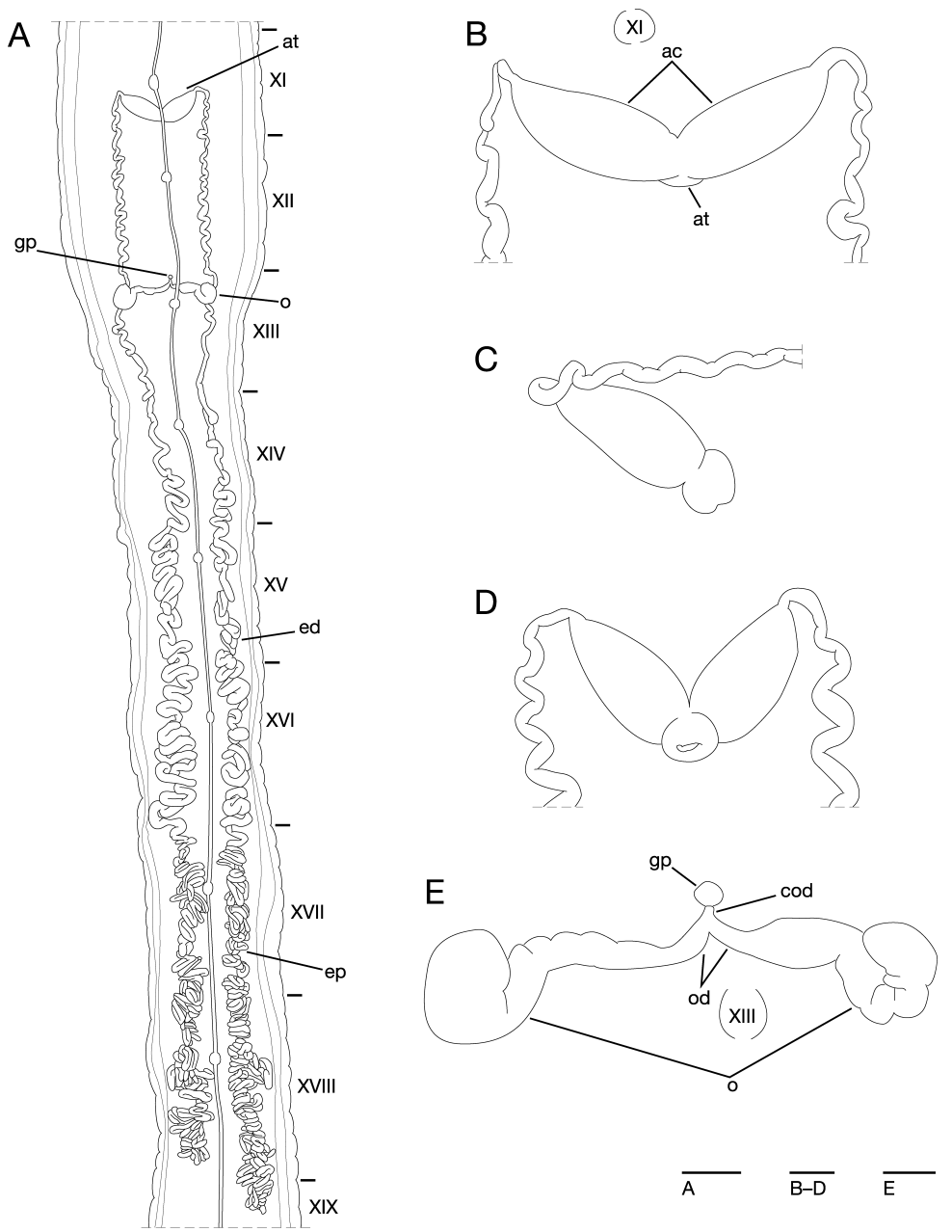

Fig. 4. Orobdella octonaria Oka, 1895, lectotype, NSMT-An 415. A, Dorsal view of reproductive system and ventral nervous system; B, dorsal view of male atrium showing position of ganglion XI; C, lateral view of male atrium; D, ventral view of male atrium; E, dorsal view of female reproductive system showing position of ganglion XIII. Abbreviations: ac, atrial cornu; at, atrium; cod, common oviduct; ed, ejaculatory duct; ep, epididymis; gp, gastropore; o, ovisac; od, oviduct. Scale bars: $5 \mathrm{~mm}$ (A); $1 \mathrm{~mm}$ (B-E).

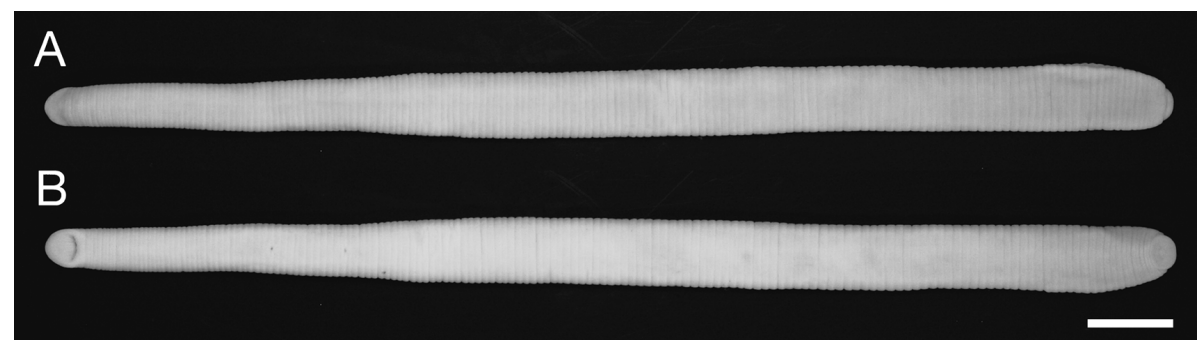

Fig. 5. Orobdella octonaria Oka, 1895, from near the type locality, KUZ Z181. A, Dorsal view; B, ventral view. Scale bar: $1 \mathrm{~cm}$.

a1 >a2>a3; a1 with slight furrow dorsally (KUZ Z181) (Fig. 7C, D).

Anterior ganglionic mass in VI a2 and b5. Ganglia VIII-X, XII, XIV-XXI in b3 and b4 of each somite. Ganglia $\mathrm{XI}$ and XIII in b4 of each somite. Ganglia XXI-XXV in b3 of each somite. Ganglion XXVI in b1 and b2. Posterior ganglionic mass in XXVI c9-c11.

Eyes three pairs, first pair dorsally on posterior margin of II, second and third pairs dorsolaterally on posterior margin of $\mathrm{V}(\mathrm{a} 1+\mathrm{a} 2)$ (Fig. 7A).

Pharynx reaching to XIV c9. Crop in XIV c9 to XXI c12.
Gastropore at middle of XIII b2 (Fig. 7E). Gastroporal duct joining with crop in XIV b2/b3. Intestine tubular, acecate, in XXI c12 to XXV b1. Rectum tubular, thin-walled.

Male gonopore at middle of XI c11. Female gonopore at middle of XIII b2. Gonopores separated by $1 / 2+10+1 / 2$ annuli. Paired epididymides in XVII b4/c9 to XIX c9/c10. Ejaculatory ducts in XI c9 to XVII b4/c9.

Distribution. Known from mountainous regions of Honshu, Shikoku, and Kyushu, Japan (Oka and Nagao 1965).

Remarks. Orobdella octonaria is easily distinguished 


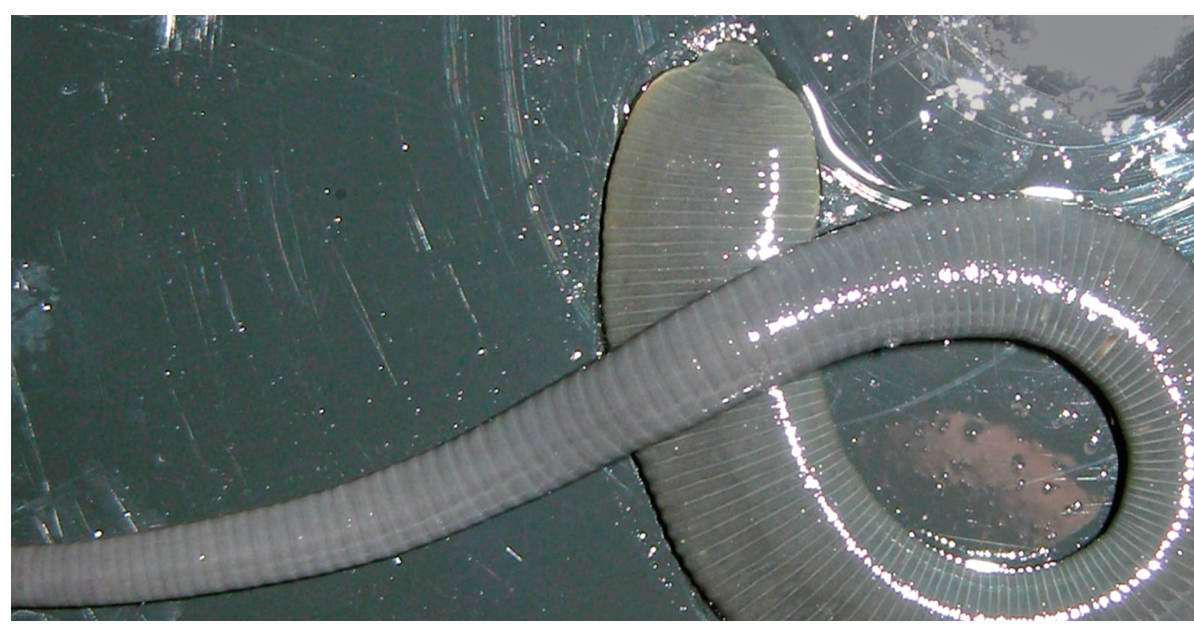

Fig. 6. Orobdella octonaria Oka, 1895, from near the type locality, KUZ Z181, photograph of live animal, dorsal view.
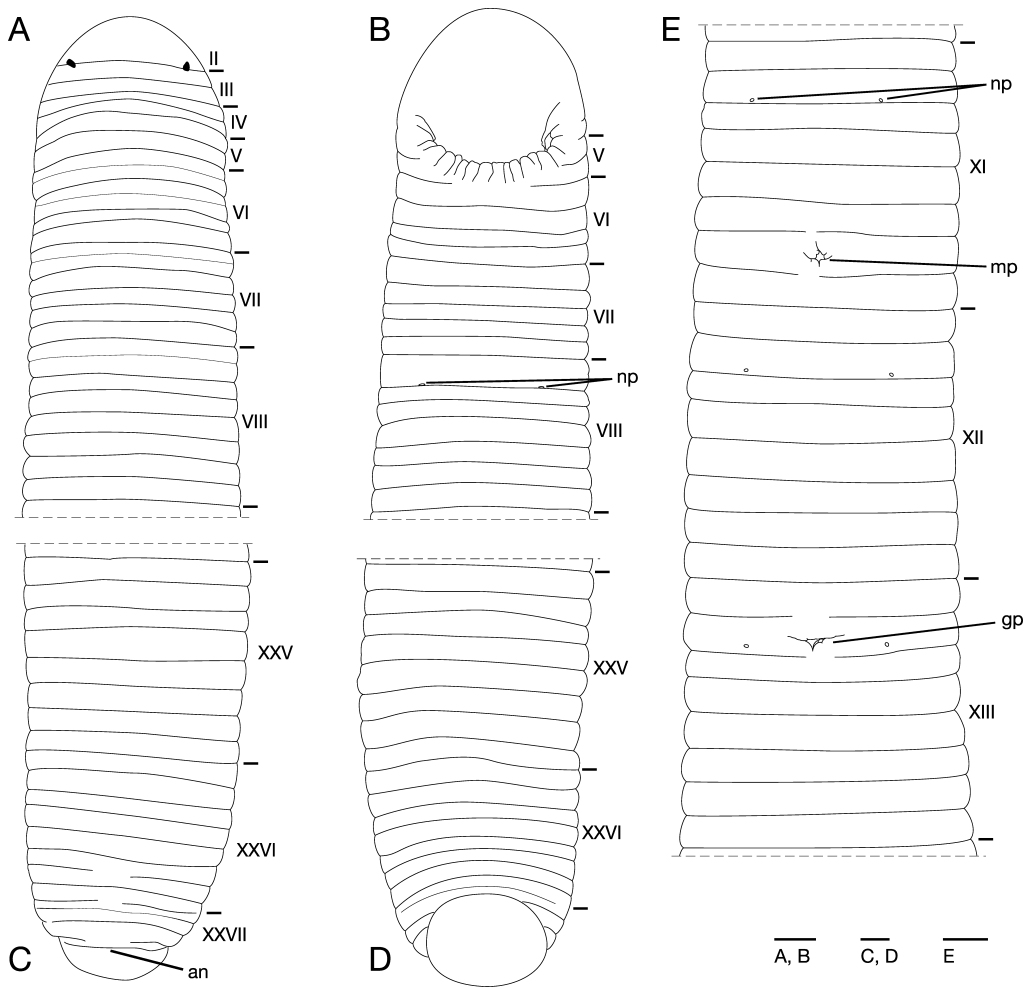

Fig. 7. Orobdella octonaria Oka, 1895, from near the type locality, KUZ Z181. A, Dorsal view of somites I-VIII; B, ventral view of somites I-VIII; C, dorsal view of somites XXV-XXVII and caudal sucker; D, ventral view of somites XXV-XXVII and caudal sucker; E, ventral view of somites XI-XIII. Abbreviations: an, anus; gp, gastropore; mp, male gonopore; np, nephridiopore. Scale bars: $1 \mathrm{~mm}$.

from the other eight species of Orobdella in having midbody somites that are octannulate. Five species, O. esulcata Nakano, 2010, O. kawakatsuorum Richardson, 1975, O. koikei Nakano, 2012, O. tsushimensis Nakano, 2011, and O. whitmani, have quadrannulate mid-body somites. Three species, O. dolichopharynx Nakano, 2011, O. ijimai, and O. shimadae Nakano, 2011, have mid-body somites that are sexannulate. Octannulate species other than O. octonaria have not been reported yet.

Richardson (1971) redescribed of O. octonaria based on a single specimen collected from Nagano Prefecture, Japan (NSMT-An 52). His specimen could not be reexamined in this study, since it was not found in the annelid collection of the NSMT. However, several points of Richardson's (1971) description are discordant with the present study. First, he noted that the female gonopore is at XIII b2 but not positioned close to the gastropore (XIII $\mathrm{cl} / \mathrm{c} 2$ in his paper, i.e., $\mathrm{XII} / \mathrm{XIII}$ in current terminology). In the lectotype and the newly obtained specimens, in contrast, the female gonopore is close to the gastropore and both pores open in the middle of XIII b2. In his description of O. kawakatsuorum, Richardson (1975b) mentioned that the female gonopore and gastropore of that species as well are not together. In actuality, these two pores are closely adjacent in the holotype and 
the newly obtained specimens (Nakano 2012). In addition, the female gonopore in all the other gastroporous species of Orobdella is also close to the gastropore (Nakano 2010, 2011b, c, 2012). These facts suggest that Richardson (1971, 1975b) misjudged the positions of the female gonopores and gastropores in the species of Orobdella he studied. Richardson (1971) also noted that O. octonaria possesses a pseudopore in XIII b4/b5 (i.e., b4/c9 in current terminology), but such a pore was not detected in the specimens examined in the present study. As for the genital organs, Richardson (1971) noted that a male atrium does not exist, and that the two oviducts do not converge into a common oviduct but descend directly and separately to the female gonopore, however, O. octonaria actually does have a developed male atrium (Fig. 4B-D) and a common oviduct (Fig. 4E).

Richardson (1971) established the genus Kumabdella Richardson, 1971 for O. octonaria, diagnosed principally by its octannulate mid-body somites. He also suggested that another new genus should be erected for sexannulate $O$. ijimai. He attributed great weight to the mid-body somite annulation in leech classification, and split many genera on this basis (e.g., Richardson 1969, 1975a). Recent molecular phylogenetic studies have shown that mid-body somite annulation does not reflect phylogenetic relationships in erpobdellid (Trontelj and Sket 2000) and haemadipsid leeches (Borda and Siddall 2011). This suggests that the generic classification on the basis of mid-body somite annulation should be reconsidered in other families as well. In the case of Orobdella, Richadson's (1971) classification has not been followed by subsequent taxonomic workers (Lukin 1976; Sawyer 1986; Nakano 2011c; Oceguera-Figueroa et al. 2011; Nakano et al. 2012). Molecular phylogenetic analyses have revealed that $O$. octonaria is included in a clade of mostly quadrannulate species, and that sexannulation and octannulation evolved in parallel in Orobdella (Nakano 2012; Nakano et al. 2012). Inasmuch as O. octonaria is clearly in accord with the diagnostic characters of Orobdella as modified by Nakano (2011c), Kumabdella should indeed be regarded as a junior synonym of Orobdella, in accordance with the five post-1971 works cited above.

\section{Acknowledgements}

The author is grateful to Dr. Hironori Komatsu (NSMT) for allowing me to examine the syntype of O. octonaria under his care, and Prof. Tsutomu Hikida (Kyoto University) for his helpful comments and suggestions to improve this manuscript. I am also grateful to Dr. Rei Ueshima (The University of Tokyo) for allowing me to survey the leech collection under his care, to two anonymous reviewers, Dr. Mark J. Grygier (Lake Biwa Museum) and Dr. Hiroshi Kajihara (Hokkaido University) for their constructive comments on this manuscript, and to Dr. Elizabeth Nakajima (Kyoto University) for checking the English of this text. This study was financially supported in part by a Grant-in-Aid for Biodiversity and Evolutionary Research of Global COE (A06) from MEXT, Japan, to Kyoto University.

\section{References}

Borda, E. and Siddall, M. E. 2011. Insights into the evolutionary history of Indo-Pacific bloodfeeding terrestrial leeches (Hirudinida: Arhynchobdellida: Haemadipisdae). Invertebrate Systematics 24: 456-472.

Lukin, E. I. 1976. Fauna SSSR. Pijavki. Tom I [Fauna USSR. Leeches. Vol. 1]. Nauka, Leningrad, 484 pp. [In Russian]

Moore, J. P. 1927. The segmentation (metamerism and annulation) of the Hirudinea. Pp. 1-12. In: Harding, W. A. and Moore, J. P. The Fauna of British India, including Ceylon and Burma. Hirudinea. Taylor \& Francis, London.

Nakano, T. 2010. A new species of the genus Orobdella (Hirudinida: Arhynchobdellida: Gastrostomobdellidae) from Kumamoto, Japan, and a redescription of $O$. whitmani with the designation of the lectotype. Zoological Science 27: 880-887.

Nakano, T. 2011a. Holotype redescription of Mimobdella japonica (Hirudinida, Arhynchobdellida, Erpobdelliformes) and taxonomic status of the genus Mimobdella. ZooKeys 119: 1-10.

Nakano, T. 2011b. A new species of Orobdella (Hirudinida: Arhynchobdellida: Gastrostomobdellidae) from Tsushima Island, Japan. Species Diversity 16: 39-47.

Nakano, T. 2011c. Redescription of Orobdella ijimai (Hirudinida: Arhynchobdellida: Gastrostomobdellidae), and two new species of Orobdella from the Ryukyu Archipelago, Japan. Zootaxa 2998: $1-15$.

Nakano, T. 2012. A new species of Orobdella (Hirudinida, Arhynchobdellida, Gastrostomobdellidae) and redescription of O. kawakatsuorum from Hokkaido, Japan with the phylogenetic position of the new species. ZooKeys 169: 9-30.

Nakano, T. and Itoh, T. 2011. A list of the leech (Clitellata: Hirudinida) collection deposited in the Department of Zoology, The University Museum, The University of Tokyo. The University Museum, The University of Tokyo. Material Reports 90: 85-94.

Nakano, T., Ramlah, Z. and Hikida, T. 2012. Phylogenetic position of gastrostomobdellid leeches (Hirudinida, Arhynchobdellida, Erpobdelliformes) and a new family for the genus Orobdella. Zoologica Scripta 41: 177-185.

Oceguera-Figueroa, A., Phillips, A. J., Pacheco-Chaves, B., Reeves, W. K. and Siddall, M. E. 2011. Phylogeny of macrophagous leeches (Hirudinea, Clitellata) based on molecular data and evaluation of the barcoding locus. Zoologica Scripta 40: 194-203.

Oka, A. 1895. On some new Japanese land leeches. (Orobdella nov. gen.). Journal of the College of Science. Imperial University, Japan 8: 275-306.

Oka, A. 1910a. Key to Japanese leeches. Dobutsugaku Zasshi 22: 56-64. [In Japanese]

Oka, A. 1910b. Synopsis der japanischen Hirudineen, mit Diagnosen der neuen Species. Annotationes Zoologicae Japonenses 7: 165183.

Oka, A. and Nagao, Z. 1965. Orobdella octonaria Oka. P. 574. In: Okada, Y., Uchida, S. \& Uchida, T. (Eds.) New Illustrated Encyclopedia of the Fauna of Japan, Part 1. Hokuryu-kan, Tokyo. [In Japanese]

Richardson, L. R. 1969. A contribution to the systematics of the hirudinid leeches, with description of new families, genera and species. Acta Zoologica Academiae Scientiarum Hungaricae 15: 97-149.

Richardson, L. R. 1971. Gastrostomobdellidae f. nov. and a new genus for the gastroporous Orobdella octonaria Oka, 1895, of Japan (Hirudinoidea: Arhynchobdellae). Bulletin of the National Science Museum, Tokyo 14: 585-602.

Richardson, L. R. 1975a. A contribution to the general zoology of the land-leeches (Hirudinea: Haemadipsoidea superfam. nov.). Acta Zoologica Academiae Scientiarum Hungaricae 21: 119-152. 
Richardson, L. R. 1975b. A new species of terricolous leeches in Japan (Gastrostomobdellidae, Orobdella). Bulletin of the National Science Museum Series A (Zoology) 1: 39-56.

Sawyer, R. T. 1986. Leech Biology and Behaviour. Clarendon Press, Oxford, $1065 \mathrm{pp}$.

Soós, Á. 1966. Identification key to the leech (Hirudinoidea) genera of the world, with a catalogue of the species. III. Family: Erpobdellidae. Acta Zoologica Academiae Scientiarum Hungaricae 12: 371-407.

Trontelj, P. and Sket, B. 2000. Molecular re-assessment of some phylogenetic, taxonomic and biogeographic relationships between the leech genera Dina and Trocheta (Hirudinea: Erpobdellidae). Hydrobiologia 438: 227-235

\section{Addendum}

After this manuscript was accepted for publication in the
Species Diversity, two new species of the genus Orobdella, $O$. mononoke Nakano, 2012 and O. ketagalan Nakano and Lai, 2012, have been described (Nakano 2012; Nakano and Lai 2012). Orobdella octonaria is distinguished from these two new species in having mid-body somites that are octannulate. Orobdella ketagalan and O. mononoke have quadrannulate mid-body somites, and sexannulate mid-body somites respectively.

Nakano, T. 2012. A new sexannulate species of Orobdella (Hirudinida, Arhynchobdellida, Orobdellidae) from Yakushima Island, Japan. ZooKeys 181: 79-93.

Nakano, T. and Lai, Y.-T. 2012. A new species of Orobdella (Hirudinida, Arhynchobdellida, Orobdellidae) from Taipei, Taiwan. ZooKeys 207: 49-63. 